\title{
Innovation Goals in Software Development for Business Applications
}

\author{
Bob Arnold*, M. Reza Shadnam* \\ ${ }^{*}$ R\&D Incentives Group, KPMG, Vancouver, Canada \\ Email: mshadnam@kpmg.ca
}

\begin{abstract}
Keywords: Standard engineering Current research, Web services, Technological uncertianty, Experimental development
\end{abstract}

\begin{abstract}
Having been in touch with technical side of many companies in various coctors, we know industry is facing a period of unprecedented change. We have compiled a st of mon technological challenges in the sector that companies are facing in adapting to the change The purpose of this contribution is to discuss and communicate areas where technologio halleng sin the Software Development Sector lie. We see this kind of inventory ber cticlal to aca emic community as it provides an account of industry challenges. The anal s wou be no ssary to really assist players in the sector in being better prepared for forma learning and know-how development. Beside knowledge manage nent ben the analysis also would help in taking advantage of research and development fu a and attra g investors; both academic and industrial organizations can take advantage of ti aspo we are calling this type of analysis "capabilities analysis". A single company might wo lve the 1d/s technical problems, but just being aware of them and measuring steps taken 0 advance, even s, ightly, in the direction of solving the problems presented in this analysis would hake the cornpany stand out. When data is formulated this way, strong evidence is created that th roject go $s$ beyond standard engineering by distinguishing risk that can be eliminated through $\mathrm{ex}_{\mathrm{l}}$ from standard engineering risk. The main contribution of this work is classific problems and approaches to solve them in this field.
\end{abstract}

\section{INTRODUCTION}

Companies are facing cha ang tew technology, deliver process improvements, create added value product and deve new business models. At the R\&D group of KPMG, we are always interested in ss ing the en fing trends in the industry. We work with a number of many major companies $n$ var sectors. We help our clients understand emerging trends, build for the future and stay ahead ceir competitors by taking optimal advantage of available governmental fy ding $\mathrm{m}$ chanisms.

This contriou, inten $d$ to serve as an account of technological uncertainties, challenges and difficilties in com puting science and software development industrial research and develop nen. Javing ked with the R\&D side of hundreds of IT product development and syste inte ators and IT departments within companies it is amazing to see that number of common murvomal challenges in the sector is limited. Companies are trying to solve similar problems, h clearly define state of the art in the sector; but in many cases they do not share their solutions with each other because of IP ownership issues. Such a list of current technological problems in the industry sector would be helpful to both academics and students focus on more industry relevant projects, which would entail more interest and investment from industry and governmental granting agencies. Some of the funding agencies/programs require industrial partners and/or partial funding through industry and for some others formal expression of interest from industry/companies in form of a letter of interest is required (e.g. some of NSERC funding mechanisms). The authors would be pleased to put research groups in touch with possible industrial partners. Last but not least would be better absorption of students in the industry job market. 


\section{INNOVATIONS IN THE BUSINESS SECTOR}

Projects in companies could be grouped into 4 categories (see Table 1):

Table 1. Innovative business project classification

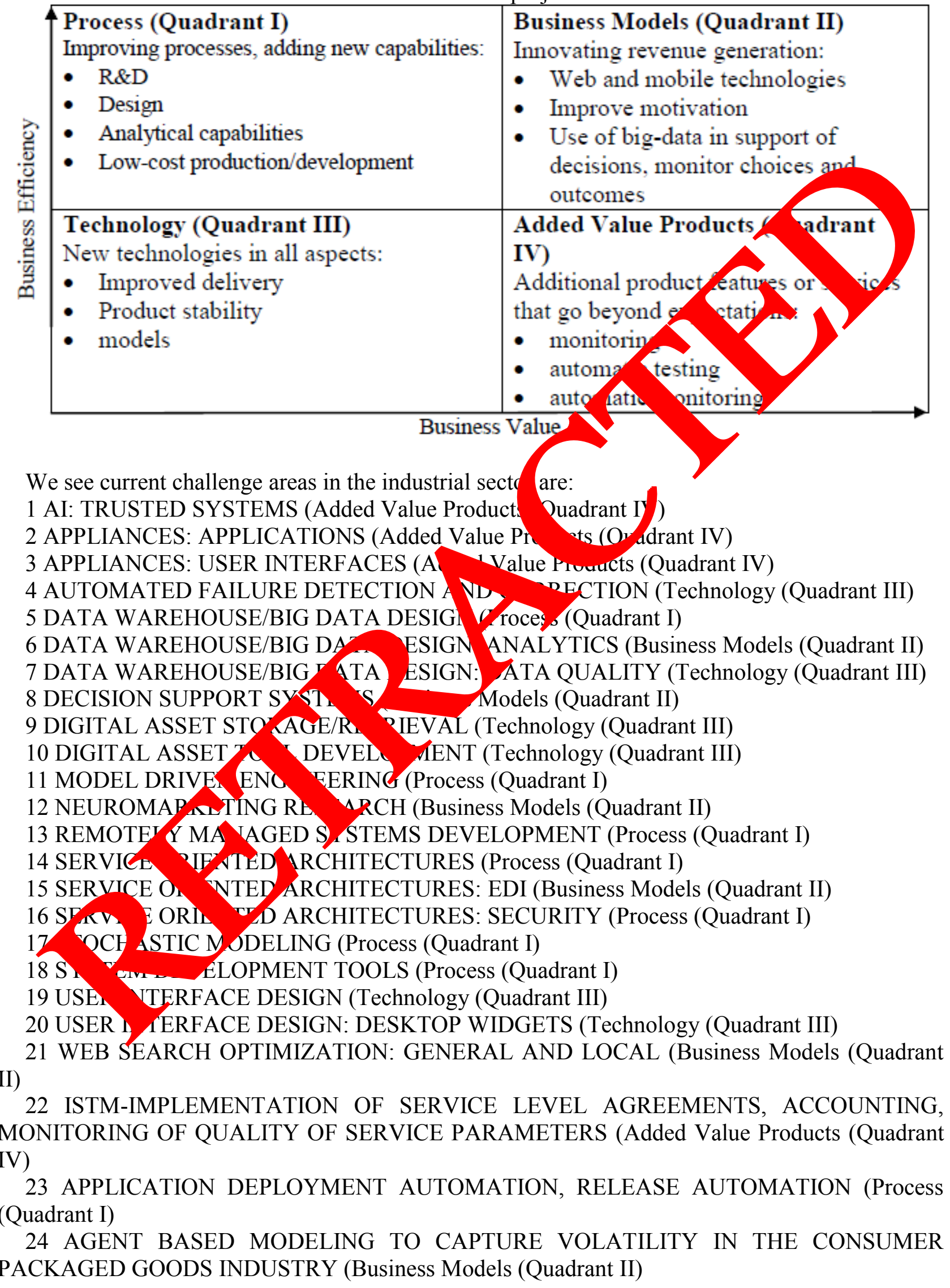




\section{SCHEDULING IN DISTRIBUTION NETWORKS IN A DYNAMIC ROUTING ENVIRONMENT (Business Models (Quadrant II) \\ 26 DEMAND FORECASTING IN A SUPPLY CHAIN (Business Models (Quadrant II)}

Here we would focus on 3 of the above listed areas. Two categories of approaches are out there for solving problems in these challenging areas:

1) There are some good approaches to challenging problems that just need use of routine engineering approaches to tackle with (such as trial and error) and

2) There are approaches that require moving beyond standard methods and merit research and development. These problems are the focus of this contribution.

\section{Service Oriented Architectures: Security}

The Table 2 below evaluates technical risks that can be mitigated through sta ard engin ing approaches (first category). Where a standard engineering approach is not compl $\mathrm{v}$ effecti in mitigating the specified risk, further non-routine engineering may be neces ary and have coted this by adding the tag, "see below" to the mitigation.

Table 2. Standard Engineering Approar es

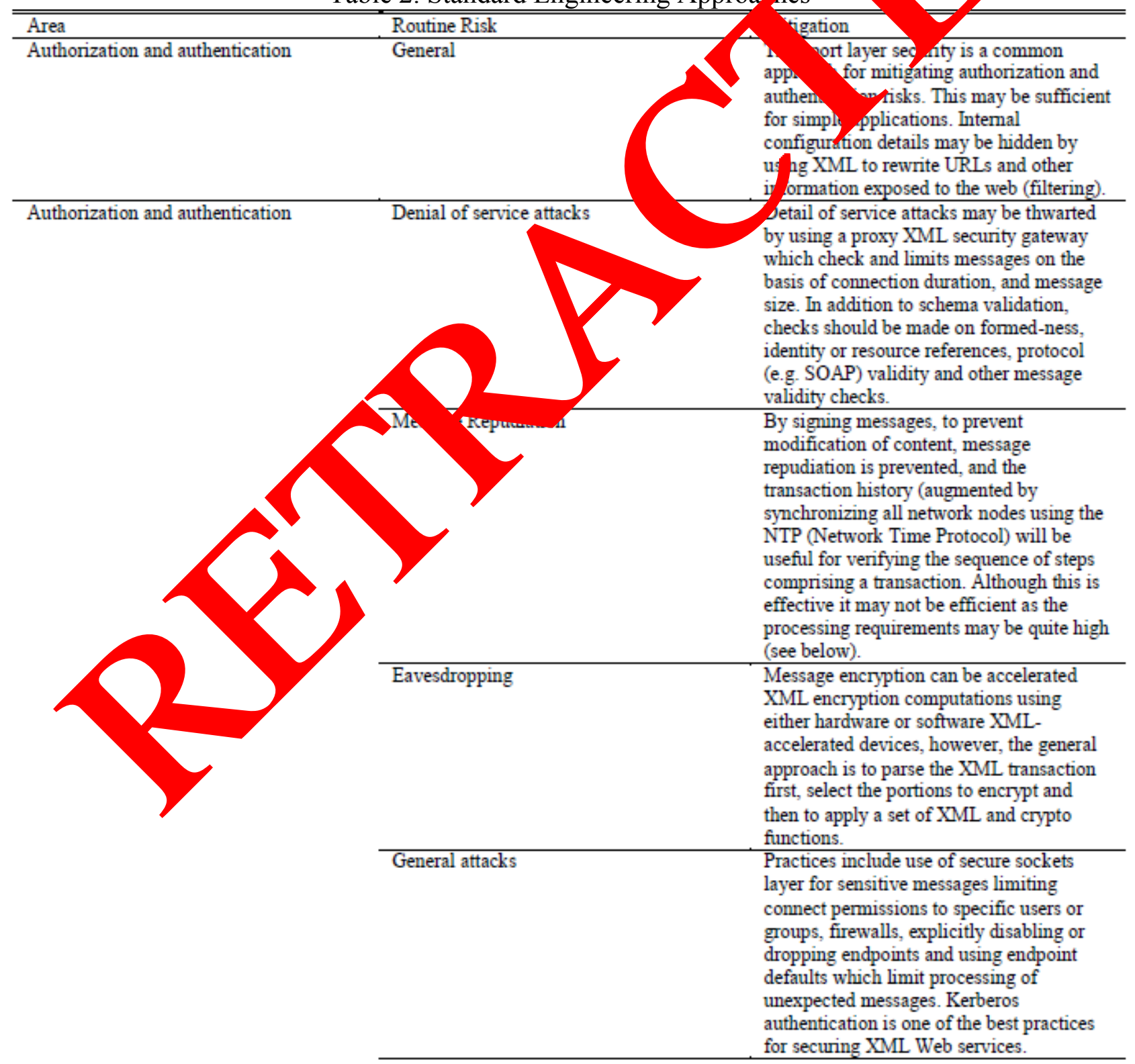


Revocation of credentials Method of synchronizing revocation of credentials among jurisdictions in a federation, which is able to handle nonresponding jurisdictions and similar enrors, has not been developed.

Issues exist in the area of distributed Method for securely distributing synchronization configuration files and federation keys has not been developed

\begin{tabular}{ll}
\hline Authorization and authentication & $\begin{array}{l}\text { Revocation of federation keys on } \\
\text { withdrawal of a jurisdiction }\end{array}$ \\
\hline Attacks & $\begin{array}{l}\text { Cross site scripting and potential theft of } \\
\text { cookies }\end{array}$
\end{tabular}
The browser is the weak spot Cross site scripting and potential theft of DACS, single sign-on and role-based security system for Apache or server-based software, which provides authentication and rule-based authorization for any web service or CGI program. Th model is only a concep wa not implemented by DA? a workaround by 2 ing DACS to Although t invoke HTTP ulests valemal D, S translatig betwee DACS

\begin{tabular}{ll}
\hline Revocation of federation keys & Modification of web services to accept \\
& DACS cookies non uniform and complex. \\
\hline Area & Routine Risk \\
\hline Attacks & DACS relies on cookies \\
\hline
\end{tabular}

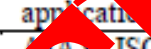

The Table 3 below outlines current research in limitations on those conclusions. Metrics for the proble outlined. Problems in second category represent curre approaches outlined in Table 3 should not be amena appearing in the Table 3 .

Table 3. Experimental ever

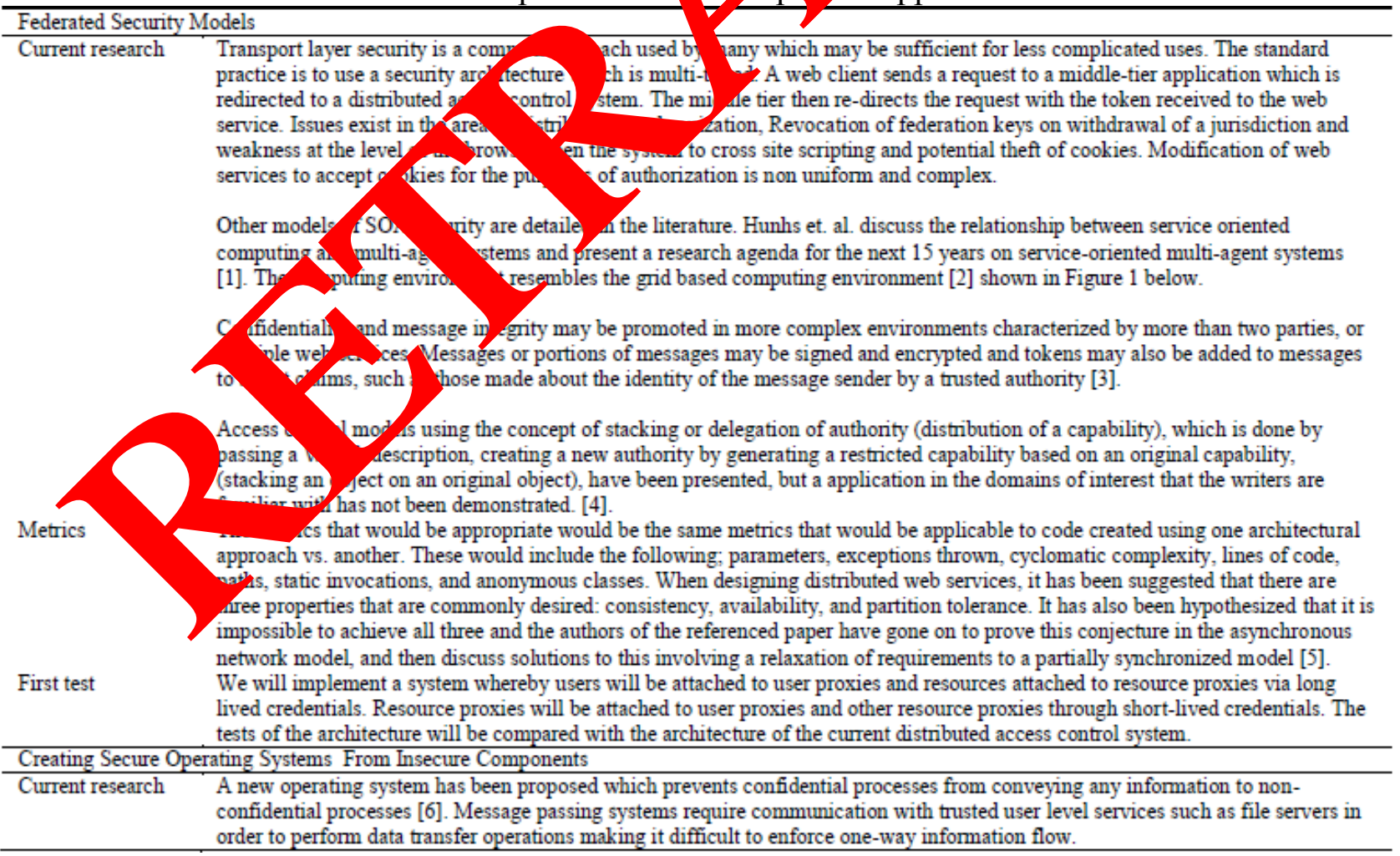




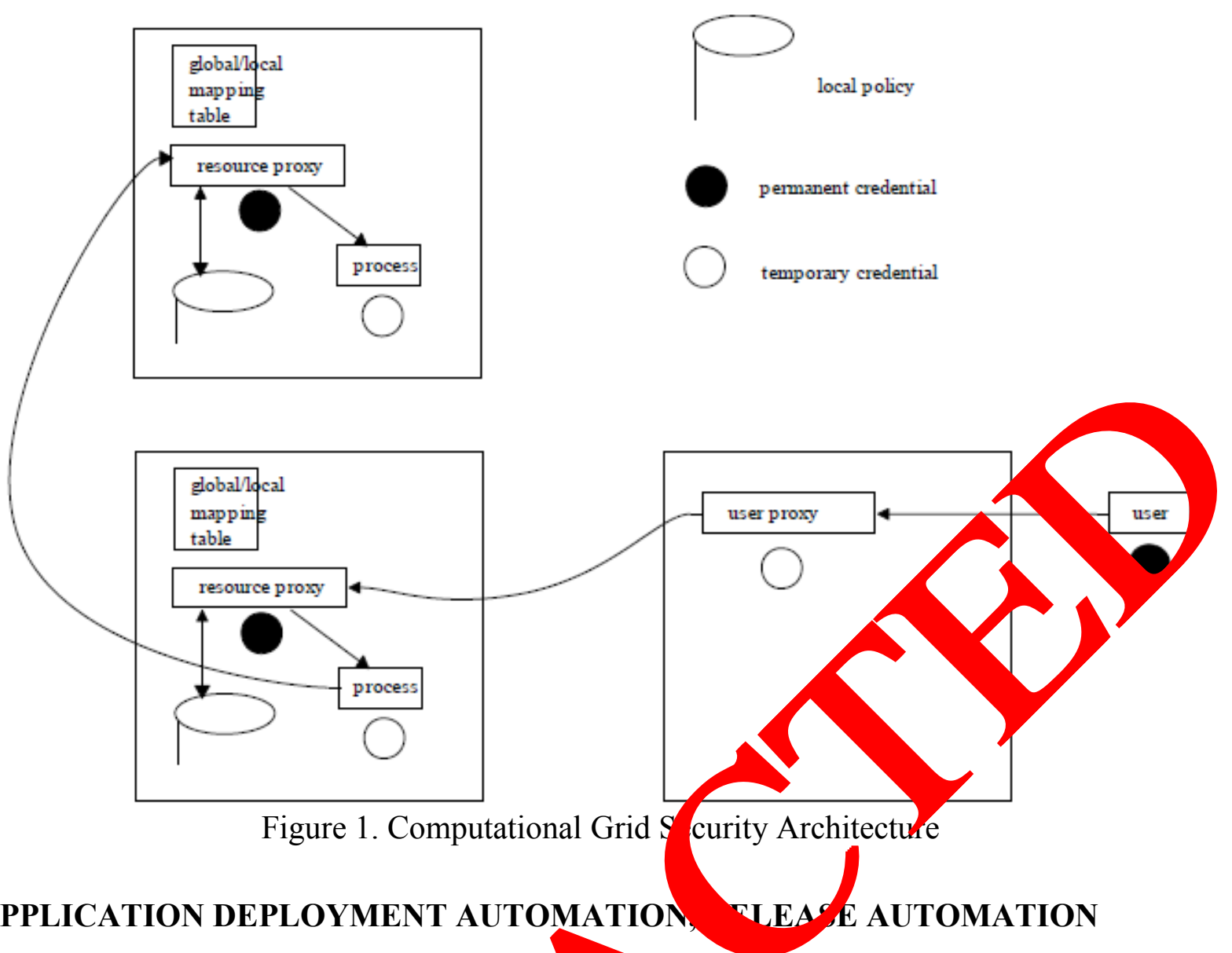

\section{APPLICATION DEPLOYMENT AUTOMATION NLEA E AUTOMATION}

The Table 4 below evaluates all technic that can be mitigated through standard engineering approaches (first category).

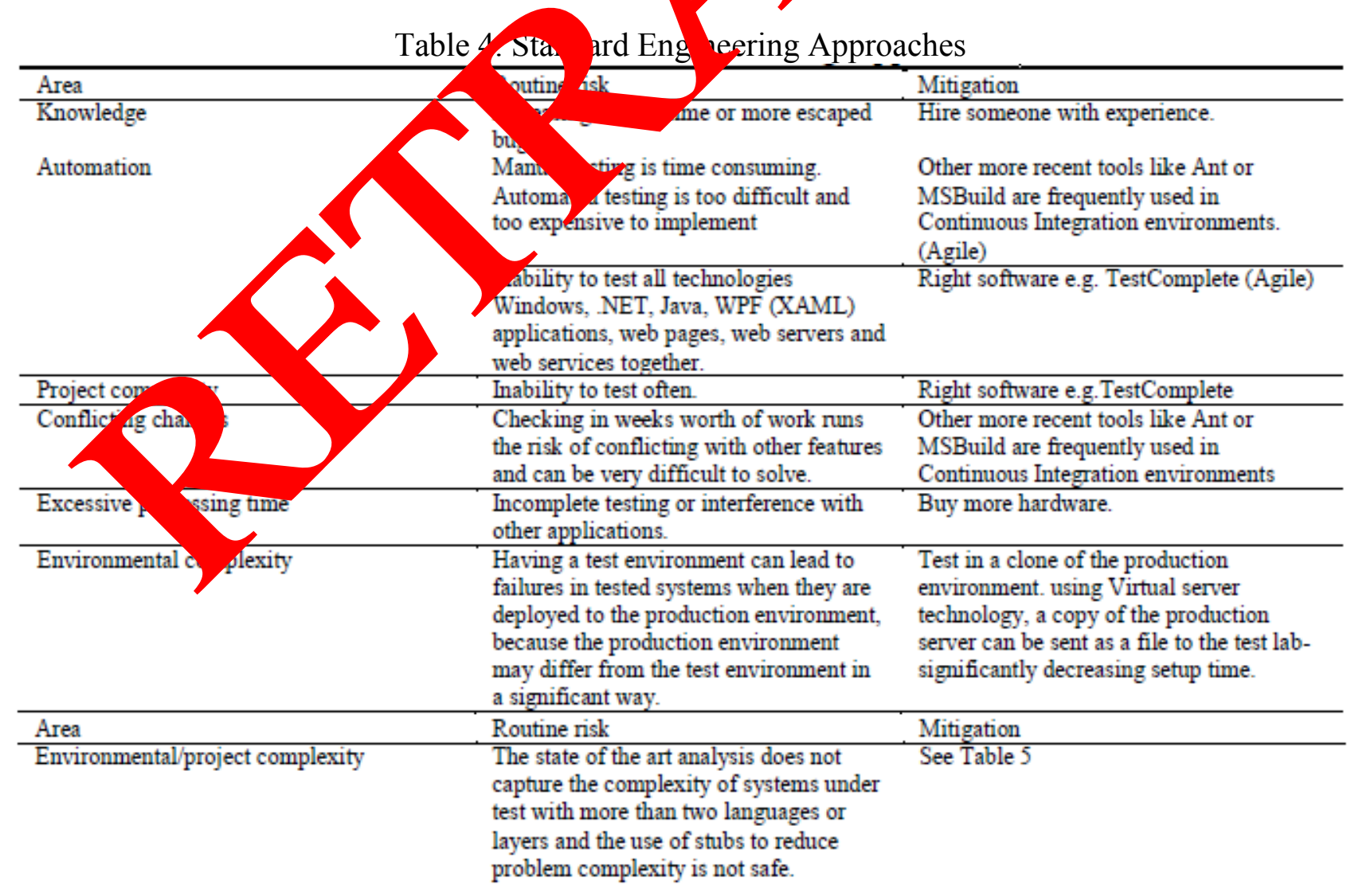


GUIs, B2B and other asynchronous communicating systems

Test Tools for Service Oriented Architectures
The standard approach in which generation of test cases which model all states becomes a difficult task when a GUI is the module under test. Although A solution is proposed to allow the tester to generate and save naive scripts this is at the stage of bench top.

Most testing tools are incapable of building composite interdependent tests across technology platforms, languages and systems, rendering end to end testing of SOAs impossible using existing approaches.
See Table 5

See Table 5

The Table 5 below outlines current research in the area, including any conclusions and limitations on those conclusions. Metrics for the problem are given. A first further research st $\mathrm{P}$ is Problems in second category represent current research in the area. Table 5. Experimental Development Approach

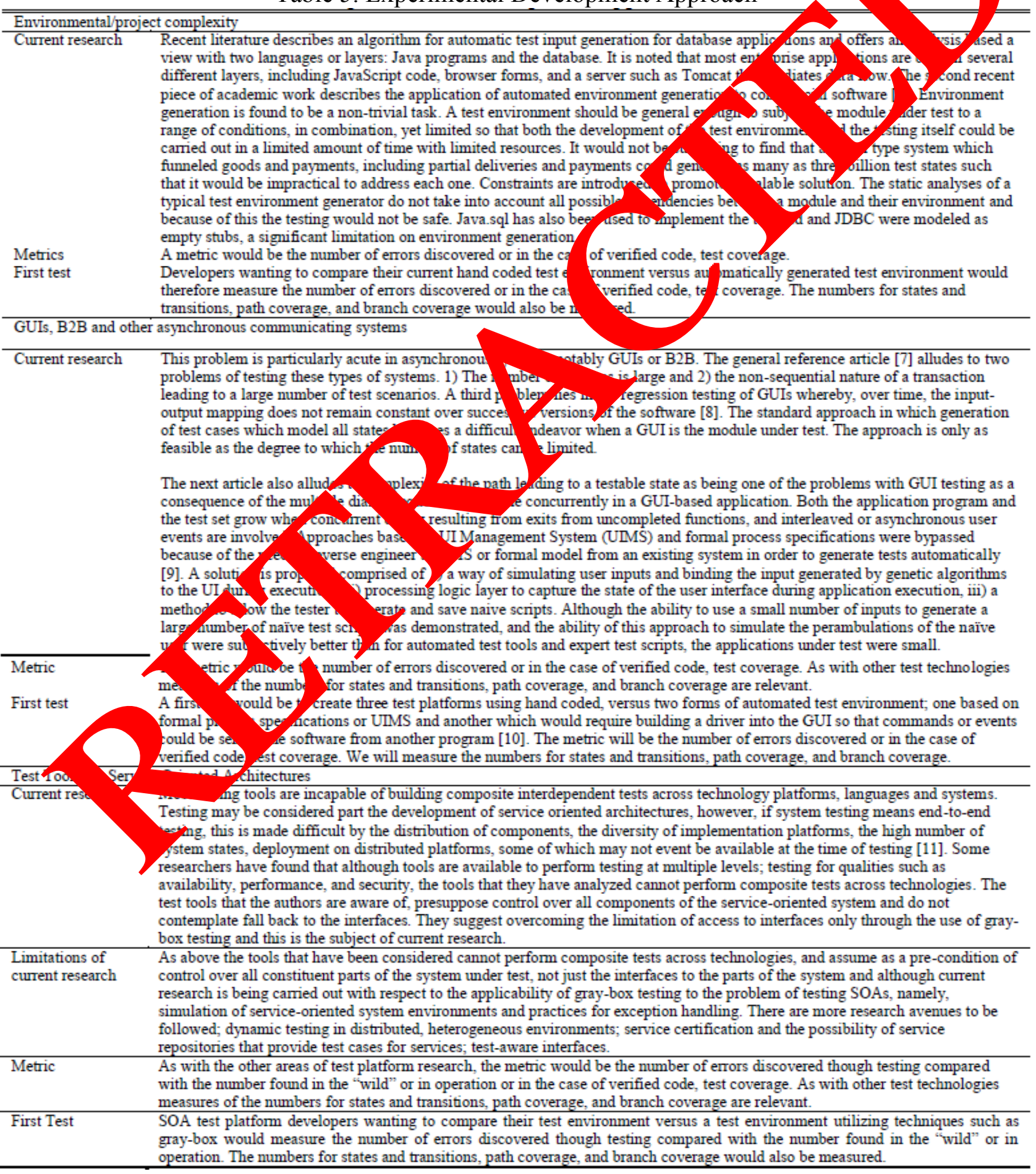




\section{DATA WAREHOUSE/BIG DATA DESIGN: DATA QUALITY}

The Table 6 below evaluates all technical risks that can be mitigated through standard engineering approaches (first category).

Table 6. Standard Engineering Approaches

\begin{tabular}{|c|c|c|}
\hline Area & Routine Risk & Mitigation \\
\hline \multirow[t]{8}{*}{ Data quality } & Production data quality problems & $\begin{array}{l}\text { Verify that a database refactoring is } \\
\text { required, choose the most appropriate } \\
\text { database refactoring, deprecate the original } \\
\text { schema, write unit tests, modify the } \\
\text { database schema, migrate the source data, } \\
\text { update extemal access programs update } \\
\text { your data migration script } \\
\text { regression tests, annoy ce the refac } \\
\text { version control your }\end{array}$ \\
\hline & $\begin{array}{l}\text { Patterns in the data which suggest that } \\
\text { some cleanup may be required, missing } \\
\text { data, non-conformed fields, outliers in the } \\
\text { data, duplicates in the data (i.e.) one } \\
\text { customer may have two addresses and two } \\
\text { customer Ds }\end{array}$ & $\begin{array}{l}\text { Extract, transform, loa database } \\
\text { functions that ombin to one to } \\
\text { pull data oy of one databasc }\end{array}$ \\
\hline & $\begin{array}{l}\text { Patterns in the data which suggest that } \\
\text { some cleanup may be required, missing } \\
\text { data, non-conformed fields, outliers in t } \\
\text { data, duplicates in the data (i.e.) one } \\
\text { customer may have two addresseg } \\
\text { customer Ds }\end{array}$ & $\begin{array}{l}\text { In wal control } t \text { als are required for } \\
\text { what received, adjusted, excluded } \\
\text { (errors } \\
\text { errors from previous cycle), output } \\
\text { (extracts and data marts) }\end{array}$ \\
\hline & $\begin{array}{l}\text { Inability to calculate summar atistics } \\
\text { without having to perform col joins }\end{array}$ & De normalization and a star schema design \\
\hline & $\begin{array}{l}\text { Need to decompose the data sub } \\
\text { data entities comp facts and } \\
\text { dimensions. }\end{array}$ & $\begin{array}{l}\text { imensional (logical) model (cube). Entity- } \\
\text { relationship model, star schemas, } \\
\text { snowflake schemas, fact-constellation } \\
\text { schemas, persistent multidimensional } \\
\text { stores, summary tables. The challenge, } \\
\text { given a set of databases that are already } \\
\text { decomposed into data entities is to } \\
\text { transpose this model to a star schema } \\
\text { arrangement of facts and dimensions } \\
\text { without losing the meaning of the data. }\end{array}$ \\
\hline & & $\begin{array}{l}\text { Mitigation is through analysis to find the } \\
\text { best source, and in the longer term, build } \\
\text { synchronization functions or work towards } \\
\text { consolidation to a single "source of truth" } \\
\text { database. }\end{array}$ \\
\hline & $\begin{array}{l}\text { 1. sing or incorrect data leads to errors in } \\
\text { information derived from data }\end{array}$ & $\begin{array}{l}\text { Profiling to discover anomalies, validity } \\
\text { assessment by measuring conformance } \\
\text { with business rules, and accuracy } \\
\text { assessment through sampling. }\end{array}$ \\
\hline & $\begin{array}{l}\text { Missing or incorrect data leads to errors in } \\
\text { information derived from data }\end{array}$ & $\begin{array}{l}\text { Assign trust factors to each data source and } \\
\text { include a "decay factor." As data gets older, } \\
\text { the trust factor declines. (Sanlam gets a } \\
\text { new look on life with customer data) }\end{array}$ \\
\hline
\end{tabular}

The Table low outlines current research in the area, including any conclusions and limitations on those cong asions. Metrics for the problem are given. A first further research step is outlined. Problems in second category represent current research in the area. 
Table 7. Experimental Development Approaches

\begin{tabular}{ll}
\hline \hline Data Quality & \\
\hline Current research & $\begin{array}{l}\text { Statistical process control (SPC) can be used for early identification of data anomalies; an automated statistical control framework } \\
\text { could be developed to detect when the process variables or inputs to the second stage of the data warehouse in this case were out of } \\
\text { control. Although bands of routine variation for both the individual values and the moving ranges, the choice of which processes to } \\
\text { monitor, and the frequency, natural batch and which variables to observe has not been studied much in practice [10]. }\end{array}$
\end{tabular}

Some authors feel that no tools for data mining exist or that the existing tools are not effective and propose a rethinking of methodologies, models, and techniques and of course a set of requirements for the technology for implementing the data flow process [11]. The main components introduced are described as; an integrator which integrates in a coordinated fashion data from operational databases, from the DW, and from other data streams; a repository capable of storing short-term data for quick retrieval, for the purpose of rule application and mining; a module that computes hierarchies of indicators to feed dashboards and reports; tools for extracting patterns out of the data streams; a module which monitors the events and sends messages to the users.

Data latency or the interval between an event through a transforming process of the data coming from databases as well as from data input streams is a process variable that we seek to minimize. Although this might be achieved through the techninass of dynamic integration, such as by query writing on heterogeneous sources which has been reported to have bee prototype, however it is conjectured by the authors of one paper that most of the cleaning techniques devise (purge/mer duplicate detection) rely on a materialized integrated level.

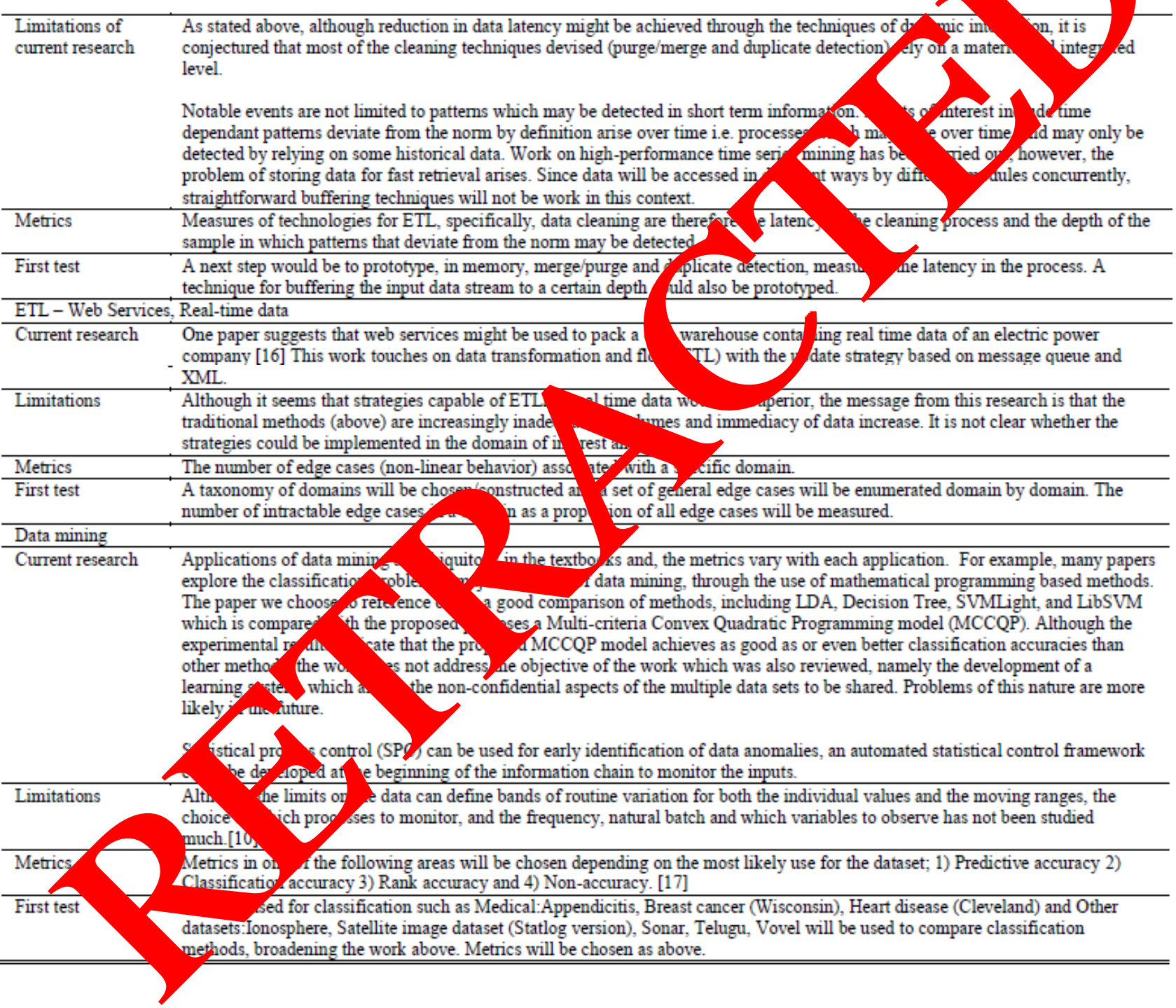




\section{DATA WAREHOUSE/BIG DATA DESIGN: ANALYTICS}

The Table 8 below evaluates all technical risks that can be mitigated through standard engineering approaches (first category).

Table 8. Standard Engineering Approaches

\begin{tabular}{lll}
\hline Area & Routine Risk & Mitigation \\
\hline Complexity & $\begin{array}{l}\text { Inability to process large amounts } \\
\text { of complex data in a timely way } \\
\text { More complex queries that involve }\end{array}$ & $\begin{array}{l}\text { Use columnar data stores to enhance performance. } \\
\text { General use of query optimizers. Technologies such as }\end{array}$ \\
& Hadoop and MapReduce
\end{tabular}

a variety of different data sets

Inability to process large amounts of complex data in a timely way More complex queries that involve a variety of different data sets Data Visualization $\longrightarrow$ Lack of visual and other novel UI for bringing data immediately to the attention of the user

Use of real time data integration technologies such as data virtualization

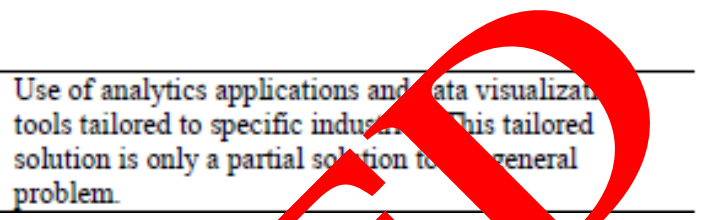
The Table 9 outlines current research in the area, including any conclusio s and I vitatio conclusions. Metrics for the problem are given. A first further research sco, octined.

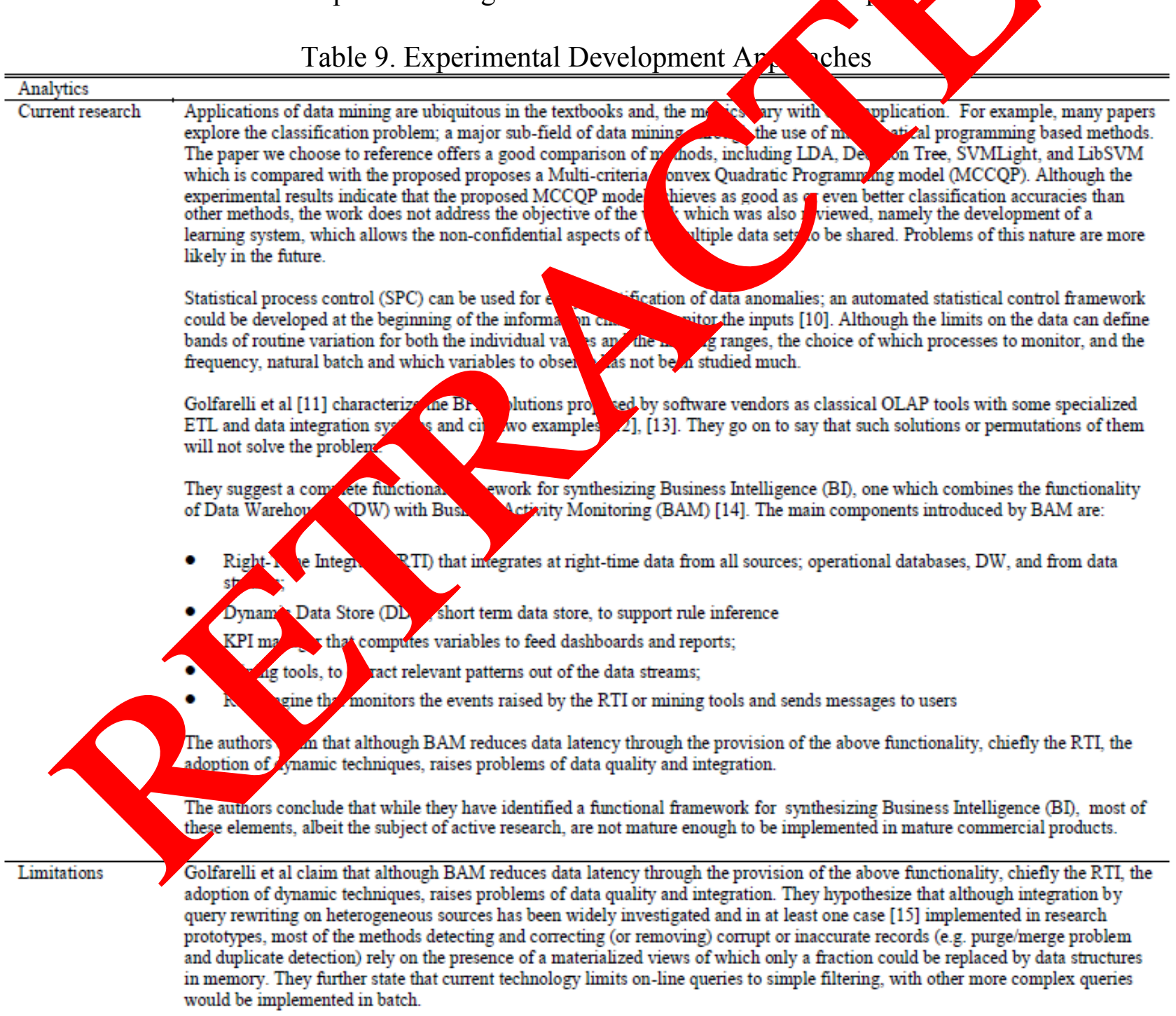

Golfarelli et al. [11] conclude with four research challenges including reduction of data latency discussed in the paragraph above;

The informative value of a BPM system is chiefly related to the types of rules and variables supported, the relationships between variables, inference of patterns/limits using historical data, and detection of out of control processes. High volume processing and storage techniques will also be needed.

Visual and other novel UI for bringing data immediately to the user.

Development of light tools to streamline the transformation of business process models to executable code. 


\section{CONCLUSIONS}

We have demonstrated a type of analysis that we are calling "capabilities analysis" which consists of an inventory of common technical challenges in the computing science and software development sector summarizing standard engineering practice in the area, and also what is not known about the area. When data is formulated this way, strong evidence is created that the project goes beyond standard engineering by distinguishing risk that can only be eliminated through experiment; therefore, technical merit would formally be established for further research and more R\&D funding through governmental and non-governmental sources would be justified. The analysis would be necessary to assist players in the sector in being better prepared for formalizing and documenting their learning and know-how development.

\section{REFERENCES} [1] M. N. Huhns and M. P. Singh, "Research Directions for Service-Oriented Multio tt Syste hs",
IEEE Internet Computing, vol. 9, pp. 65-70, 2005.

[2] I. Foster, et al., "A Security Architecture for Computational Grids" th A Conj, rence on Computer and Communication Security, 1998, pp 83-92.

[3] P. Kearney, "Message Level Security for Web Services" nformatio Secrity Technical Report, vol. 10, pp. 41-50, 2005.

[4] M. Mabuchi, et al., "An Access Control Model for Web- re vices t Supports Delegation and Creation of Authority", Proceedings of the Seventh Inter ational Confer on Networking, 2008,
pp. 213-222.

[5] S. Gilbert and N. Lynch, "Brewer's Conjecture d the Feas pility of Consistent Available Partition-Tolerant Web Services", ACM SIGACT News, 33, pp 1-59, 2002.

[6] N. Zeldovich, "Securing Untrustworthy ffware us normation Flow Control", Thesis submitted to the Department of Computing Scic a artial fulfillment of the requirements for the degree of Doctor of Philosophy, 2007.

[7] O. Tkachuk and S. P. Rajan, S "Applic tion of Automated Environment Generation to Commercial Software", Proceedin sof 2006 is oynational Symposium on Software Testing and Analysis (ISSTA '06), 2006, pp

[8] http://en.wikipedia.org/w/4/UU_tware_testing accessed at July 22, 2010.

[9] D. J. Kasik and H. G orge, "To .d A Automatic Generation of Novice User Test Scripts", Proceedings of the Con ren numan Factors in Computing Systems : Common Ground, 1996, pp. 244-251.

[10] C. Maurer, Data Warehous g: Ensuring Data Integrity with End-to-End and Statistical Process Contrg Info mutic Management, vol. 7, 2007.

[11] M. Golfaren st al., ' Seyond data warehousing: what's next in business intelligence?", Proceedi on the $\lambda$ CD international workshop on Data warehousing and OLAP, 2004, pp. 16.

[12] Tst istante: Product Overview., http://www.istantesoftware.com

[13] D. So en, and H. Morris, "BusinessFactor: Event-Driven Business Performance Manager". TIBCO Whito per, 2004.

[14] H. Dresner, "Business Activity Monitoring: BAM Architecture", Gartner Symposium ITXPO, 2003.

[15] D. Beneventano, et al., "Information Integration: The MOMIS Project Demonstration", Proceedings VLDB Conference, 2000, pp. 1-4.

[16] T. Singh, et al., "Service Oriented Architecture Based Electric Power Real-time Data Ware House", International Journal of Engineering and Management Research, Vol. 2, pp. 48-56, 2012.

[17] G. Schroder, et al., "Setting Goals and Choosing Metrics for Recommender System Evaluations", European Social Fund and Free State of Saxony under grant agreement 080954843 , 2010. 